\title{
The Proximity Paradox: How Distributed Work Affects Relationships and Control
}

\author{
Rebecca Downes \\ School of Management \\ Victoria University of Wellington, New Zealand \\ rebecca.downes@vuw.ac.nz
}

\begin{abstract}
Interview data is used to examine how managers enact organizational control when separated from their direct reports by geographic distance. Findings suggest that a need for additional context drives managers to cultivate deeper relationships with their staff, creating an unexpected outcome: working at a distance means managers feel closer to their staff. A theoretical framework demonstrating how context and relationships are related to organizational control is presented and implications for distributed work and organizational control research are discussed.
\end{abstract}

\section{Introduction}

For as long as distributed organizations have existed issues of co-ordination and communication have been a central concern [1, 2]. However, improvements in communication and collaboration technologies have lent new urgency to the need for organizations to understand how to manage remote work well. Facilitated by new technologies, organizations can offer staff greater flexibility in where they work and workers are responding: a recent Gallup poll found a four-fold increase between 1995 and 2015 with $37 \%$ of workers conducting work remotely [3]. While both organizations and workers can benefit from remote work, organizations must ensure they manage these new work arrangements successfully.

This research explores an increasingly important but under-examined aspect of remote work: how managers enact organizational control when managing remote workers. It examines what managers do differently when more traditional, observation-based monitoring is limited by physical distance from staff. Limits to observation-based monitoring have implications for organizational control in particular. Implementing organizational control: that is, "the mechanisms that managers use to direct attention, motivate, and encourage individuals to act in ways that support the organization's objectives" [4], is a central part of a manager's role and has traditionally relied at least in part on the ability to observe the behavior of workers [5].

While distance prevents direct observation-based monitoring and control of remote staff, managers can still use behavior controls such as rules or processes [6]. However, little is known of the behavioral controls employed by managers and, more crucially, whether managers must create or adapt control mechanisms to compensate for the lack of observation. This research addresses this empirical gap. In doing so, it highlights the importance of context in organizational control, and uncovers a proximity paradox in distributed work: working at a distance can make managers feel closer to their staff.

\section{Theoretical Background}

This research refers to individuals as 'remote' when they work at a geographic distance from their manager (and often from their teammates), and to teams as 'distributed' when the team includes at least one member who is geographically separated from their teammates. Working remotely means that neither the manager nor employee can rely on frequent in-person interaction. Infrequent in-person interaction is enforced by geographic distance, and requires the use of communication technology, so most communication between the employee and their manager is technology-mediated. While the terms remote staff and distributed teams do not capture the full complexity of configurations that distributed teams can embody, they invoke the key element of geographic distance. 


\subsection{Distributed Teams}

Considerable evidence in the virtual team literature shows that distributed teams differ from traditional, co-located teams. In particular, trust may be more important in distributed teams and develops differently [7, 8]. Distributed teams perform differently than traditional teams depending on the task and context $[9,10]$, encounter different barriers to collaboration [11, 12], face knowledge sharing challenges [13], are less effective in developing shared understanding or common ground [14, 15], and communication norms and performance develops at different rates compared to traditional teams [10, $13]$.

Webster and Staples [16], comparing distributed and face to face teams, suggest that the type of team (distributed versus co-located) alters the relationship between group outcomes or processes and the following features: observable diversity, team duration, task type, task routineness, communication media, training, leader behavior modelling, and transformational leadership.

The majority of existing research into distributed work explores the effects of geographic distance on employees, often in terms of job performance or satisfaction, or the effect on the overall team. In contrast, relatively few studies explore the effects of distributed work on managers, particularly how managers fulfill the unique requirements of their roles. This research contributes to our understanding of the managerial perspective.

\subsection{Organizational Control}

One particularly fundamental part of a manager's role is enacting organizational control. Indeed, Kreutzer, et al. [17] note: "Organizational control is one of management's most fundamental and pervasive challenges" [17]. To reap the benefits of collective action, organizations must ensure their members are working in concert towards the organization's goals, which requires a degree of control to coordinate members' actions.

In the organizational control literature, control "describes mechanisms that are enacted by managers or organizations to inform their employees of expected performance standards, to monitor and evaluate their efforts to achieve those standards, and to reward or sanction them based on how well they perform in relation to those standards" [18]. This definition implies that the controller is "taking some action in order to regulate or adjust the behavior of the controllee" [19].
Cardinal, et al. [20] further separate and define components of organizational control. Control mechanisms are the individual instruments used to implement control - for example rules, standards, or norms. Control systems are configurations of control mechanisms. Control targets are the "specific elements of organizational transformation processes (i.e., inputs, behaviors, or outputs) to which control mechanisms are intended to be applied" [20]. Cardinal, et al. [20] define three broad control target categories: input targets, which direct how people and materials enter production processes; behavior targets, which are typically rules, procedures and norms that ensure work is done is a specified manner; and output targets which specify the quantity and quality of output that is required.

Control mechanisms, the individual instruments of control, can be further understood as formal or informal mechanisms [4, 21]. Formal controls are explicit, codified, and visible: the organization's written rules and operating procedures [22]. Informal control mechanisms, on the other hand, are the "unwritten, unofficial values, norms, shared values, and beliefs that guide employee actions and behavior - less objective, uncodified forms of control" [22]. As Kreutzer, et al. [17] observe, informal control mechanisms may not be codified but they are still deliberate attempts to exert influence. To date, organizational control research has tended to focus on formal controls, particularly behavior and output controls [4].

\subsection{Control in Distributed Teams}

One notable feature in the theorizing of organizational control is the relationship between control and monitoring. Ouchi [23], whose work has been highly influential in organizational control research [4], argues that a control system "consists primarily of a process for monitoring and evaluating performance" and that "there are only two phenomena which can be observed, monitored, and counted: behavior and the outputs which result from behavior". By this reasoning, what can be controlled is in large part dictated by what can be monitored. Monitoring, in turn, relies on the ability to gather information about the object of control. Physical colocation enables considerable information gathering via observation.

In distributed teams, physical observation is no longer possible. Logically, this might suggest that managers focus on outcomes that can be measured and quantified rather than processes which must be observed. While some researchers in the virtual team literature have taken this stance [24], the research has 
not borne out this prediction. Kurland and Cooper [25] found that managers in distributed teams use a variety of control types. Felstead, et al. [26] found that managers respond to reduced visibility of their remote staff by devising and utilizing new technology-based forms of surveillance. Piccoli, et al. [27] found no relationship between team control structure and coordination in distributed teams but suggest caution in applying the behavioral controls used in traditional teams to distributed teams. Piccoli and Ives [6] found the use of behavioral controls negatively affects team trust.

Interestingly, a great deal of research on virtual teams has been conducted in lab settings or with students in temporary teams, with much less research conducted in organizational settings. Three recent reviews have found significant difference in outcomes depending on the type of virtual team and the research design [28-30]. Results from research that uses student or lab-based teams, which do not have managers with formal, organizational authority, may not generalize well to organizational settings, particularly where questions of organizational control are concerned. Therefore, more organization-based work, such as this research, is needed to understand how organizational control is used in distributed teams.

\subsection{Context}

Another critical difference between co-located and distributed work is the amount of context available. Context is defined as "The situation within which something exists or happens, and that can help explain it" or "The text or speech that comes immediately before and after a particular phrase or piece of text and helps to explain its meaning" [31]. Thus context has two (related) meanings. One is linguistic and refers to the meaning imparted to a word or phrase by surrounding words or phrases. The other is circumstantial and refers to aspects of the setting that help explain an event or entity.

Both definitions share underlying concepts. One is the need to attend to surrounding elements, and the other is that the focal element derives its meaning in part from those surrounding elements. Thus, the meaning of the object we wish to understand is in some part derived from its relationship to surrounding elements; it does not stand alone, its meaning cannot be fully understood 'out of context'. As such, context is a broad, and at heart relational, concept that goes beyond physical proximity.

Physical proximity, however, creates opportunities for intentional and unintentional observation that provides a wealth of contextual information to help interpret other people's actions. This information is used to explain and understand events and to learn about collaborators' work styles. Gross [32] notes that when people collaborate closely in workplaces, they may develop "a subtle and complex body of practices for monitoring each other's conduct and coordinating a varied collection of tasks and activities". This monitoring and coordination requires awareness of the other's activity in the workplace, production and communication on one hand and listening and watching on the other. However, to be effective and sustainable, this needs to occur almost effortlessly [32]. Building collaboration technologies that provide more than minimal workplace or context awareness is not a solved problem [32].

Lower context awareness means that team members have less access to workplace situational information - for example it will be more difficult to tell whether a teammate is having a bad day, which could explain why they were terse in conversation, or that a teammate is overloaded and needs help [33]. Context awareness also allows actors to monitor the "state, progress, [and] direction" of workplace activity to "ascertain whether they are being done and progressing as expected, to determine exactly how one's own activities need to be adjusted to mesh with the unfolding work of the colleagues, and so forth" [34]. This awareness provides a basis for deft coordination, as well as information on the effectiveness, pace and reliability of others' work. This suggests that managers' ability to identify and correct problems will be impacted by a lack of context awareness.

Being physically separated from staff will impact the monitoring data that managers can gather via observation. Less context may also impact the manager's ability to interpret the information they can gather. As such, this research seeks to answer the following research question: how does being geographically separated from staff alter managers' organizational control enactment?

\section{Method}

\subsection{Recruitment}

Participants were recruited via social media and responded to an open invitation to take part in research on remote work. All participants were screened via an initial short meeting where the researcher described what the research entailed, checked that volunteers met the inclusion criteria, and discussed the level of participation that would 
suit the participant. The interviews reported on here are part of a larger, on-going research program. Most participants took part in interviews (described here) and some opted to take part in other parts of the research as well (not described here).

The focus for this research is how managers adapt to managing remote staff. Therefore, selection criteria was that the manager had at least one staff member they considered to be remote.

This research samples 19 managers. The managers' teams ranged in size from two staff to 34 . While many of the teams worked in software companies, other industries include agriculture and public sector service providers. None of the teams had all their members located in the same city. Nine teams were located within the same country and ten teams were spread across multiple countries. In none of the teams was the manager the only remote member of the team. Instead the manager was part of a team where some or all members worked at a distance to each other.

\subsection{Data Collection}

Participating managers were in located Europe, the USA, and the Asia-Pacific region. One manager was interviewed by phone, three were interviewed in person, and the rest were interviewed via video conference software. The semi-structured interviews lasted 45-90 minutes and were recorded and transcribed for analysis. Participants were asked to talk about their team and organization, and their experience managing remote and co-located staff. A range of topics related to organizational control were explored including hiring, understanding individual performance, identifying potential problems, and corrective actions that managers might take.

\subsection{Data Analysis}

Our current understanding of organizational control does not fully encompass what occurs when managing remote employees because control mechanisms such as observation operate differently. With this in mind, data was analyzed to inductively develop theory from the data $[35,36]$. Following the Gioia methodology [36], data was first analyzed using open coding to identify initial themes emerging from the data [37]. Initial coding used in vivo codes, reflecting the participants' language. When this was not possible, codes were created using short descriptive code names [35]. Initial codes were then consolidated: codes were merged where participants used two separate phrases to describe the same or closely related concepts. Because consolidating codes lost some of the richness of the data, the codes were then replaced with longer descriptive phrases, based on the original data and analytic memos. This first order analysis identifies participant themes and begins to structure the data [36]. In the second order analysis, themes emerging from the data were examined to identify, per Gioia, et al. [36], "whether the emerging themes suggest concepts that might help us describe and explain the phenomena we are observing". The second order analysis moves from participant-centric codes to researcher-centric codes, informed by both participant data and existing theoretical concepts [36]. The themes and concepts identified in the second order analysis and the proposed relationships between them are shown in Figure 1.

\section{Findings}

The data shows that managing remote staff is in fact different to managing co-located staff. Data supporting these findings is presented in Table 1 and discussed below.

\subsection{Tracking Performance}

When asked how they knew their staff were performing well or how they identified potential problems, managers consistently identified two 'red flags' with remote staff: changes in work output and changes in communication, specifically changes in tone and quantity. For managers with remote staff, communication is one of the few behaviors that can be directly observed. Communication refers to written communication in multiple channels (email, documentation, instant messaging, etc) as well as communication behavior in video calls. This broadly matches the behavior and output categories of monitoring in the control literature.

\subsection{Context}

Context was frequently mentioned, particularly in relation to increased risk of misunderstanding. Managers acknowledge that distance can lead to a higher risk of miscommunication in the team and, should these risks eventuate, they will be more difficult to detect quickly:

"And I think what you miss though with a remote team is the color and context ... you're trying to be efficient, you're keeping everything to the point and you're including all of the relevant information. But the person reading it can kind of interpret it in a different way than what you meant". 
Table 1: Supporting data (format adapted from [35]).

\begin{tabular}{|c|c|}
\hline Theme & Representative Quote \\
\hline & Unknowns Increase \\
\hline \multirow[t]{2}{*}{$\begin{array}{l}\text { Increased risk of } \\
\text { miscommunication or } \\
\text { misalignment }\end{array}$} & $\begin{array}{l}\text { "So for me it's because, uh, the potential for danger is greater in remote culture. I think it's way easier for miscommunication to happen or } \\
\text { because again, you don't have that visual of like, oh this person walked in today and looks happy or they look sad or you don't have just like the } 15 \\
\text { minute chat at lunch or whatever. And so I think because the risk is greater, I am way more conscious of like, okay, you need to be constantly } \\
\text { guarding against it." }\end{array}$ \\
\hline & $\begin{array}{l}\text { "Here's the other thing that can happen right? One person has a miscommunication and says to somebody else: what do you think about that? Oh } \\
\text { yeah, that's a problem. And they're [sending private direct messages] back and forth and it's not, no-one even has any visibility that those two are } \\
\text { buzzing about something. So a couple of times, occasionally it's happened like two or three times, I've found that some people were talking } \\
\text { about something for a while. I had no visibility onto it, which is, it's okay, but it just kind of more surprises me in remote because there's really no } \\
\text { sense of it at all until it's finally brought to your attention versus you know, a company we would probably see people talking about stuff". }\end{array}$ \\
\hline \multirow[t]{2}{*}{ Communication is not certain } & $\begin{array}{l}\text { "It's tricky enough to get a holistic picture of someone in the same office as you and checking everything's okay. It's five times as hard to do that } \\
\text { when they're remote and you're getting little snapshots of stuff. Particularly if somebody's deliberately sort of trying to paint a rosy picture when } \\
\text { they're struggling." }\end{array}$ \\
\hline & $\begin{array}{l}\text { "It's funny because with remote, there's an extra layer of like if someone needs to complain about someone or bring you information, there's } \\
\text { another barrier that they can't just, like it doesn't come out in a side conversation, so they have to proactively come to you". }\end{array}$ \\
\hline \multirow[t]{3}{*}{ Metrics are not sufficient } & $\begin{array}{l}\text { "I don't believe that you can boil down somebodies contribution as a software developer to a number, or even a set of numbers, that you can } \\
\text { then manage towards. To say "well, you were at an } 80 \text { and you should be an } 82 \text { so you're fired". I don't think that's a thing. So, it's definitely a lot } \\
\text { more intuition and a lot more feel, I think, in terms of management, than by the numbers." }\end{array}$ \\
\hline & $\begin{array}{l}\text { "It's an interesting question because we don't have a formal way of, uh, putting a value on that. It's more, do your peers recognize that you're } \\
\text { getting work done and is your [manager] recognizing that you're getting work done?" }\end{array}$ \\
\hline & Effort Amount Changes \\
\hline \multirow[t]{2}{*}{$\begin{array}{l}\text { More time required from } \\
\text { managers }\end{array}$} & $\begin{array}{l}\text { "I would respond to pings as soon as I woke up in the morning and, you know, before I went to sleep at night. So that was obviously very } \\
\text { exhausting." }\end{array}$ \\
\hline & $\begin{array}{l}\text { "The days could be a bit long where I'd be contactable, so I'd have the chat programs on my phone so people would reach me. You know, I might } \\
\text { be at the gym early in the morning or at dinner or something and I could provide a quick answer" }\end{array}$ \\
\hline \multirow[t]{2}{*}{$\begin{array}{l}\text { More emphasis on explicit } \\
\text { information }\end{array}$} & $\begin{array}{l}\text { "We saw the artificial constraint of remote work as an advantage when it came to documentation and writing things down. I'm sure we're not the } \\
\text { first people to say that, but, so it made us focus extra hard on making wikis, putting things into issues, and being organised in a way that was fully } \\
\text { asynchronous". }\end{array}$ \\
\hline & "We have an authoritative record of everything that happened, right? We don't disagree about anything." \\
\hline \multirow[t]{4}{*}{$\begin{array}{l}\text { More intentional effort required } \\
\text { from managers }\end{array}$} & $\begin{array}{l}\text { "In some ways, I find the work more, more tiring. I'm up early and I want to have gotten through email and Slack before I have my first meeting, } \\
\text { because I don't want get into a meeting, have some big surprise, right? And sometimes .... if my team's really active ... trying to read through it is, } \\
\text { you know, is pretty difficult too." }\end{array}$ \\
\hline & $\begin{array}{l}\text { "Don't underestimate the effort. It's not the same as having them all in your office. You have to work twice as hard or more, and you'll have more } \\
\text { problems and you'll find them harder to fix." }\end{array}$ \\
\hline & "So there are a lot of things that you have to do, I call it a little bit of a tax because you have to be more intentional about almost everything." \\
\hline & Effort Type Changes \\
\hline \multirow[t]{2}{*}{$\begin{array}{l}\text { More personal information into } \\
\text { workplace }\end{array}$} & $\begin{array}{l}\text { "One of the things that I do appreciate about this team is the people do share, you know, my daughter is sick or like, you know, they bring their } \\
\text { life into it so that no, it's not all, you know, } 100 \text { percent work chatter and stuff". }\end{array}$ \\
\hline & $\begin{array}{l}\text { "We have given feedback to one of our team members that, um, we would love to see more of you and your personality in that group because we } \\
\text { feel like we don't know you as much as we would like to and it's really smart and sensible for you to ensure that your teammates do know you } \\
\text { more about you and who you are." }\end{array}$ \\
\hline More intimacy and vulnerability & $\begin{array}{l}\text { "I mean I try to be as vulnerable as possible, like I show lots of my own failures and faults. I talk about my challenges that I have personally, how } \\
\text { I'm trying to improve as a manager. I admit mistakes as soon as they happen. Um, so I try to model the, you know, the sort of vulnerability I'd like } \\
\text { to have. In our one on ones, I'll try to, when I can remember, I'll try to throw in a like awkward questions, you know, things that uh, might make us } \\
\text { both uncomfortable to talk about. And I don't do that right away. Like I do that after we've been working together for a few months. But I find that } \\
\text { that is helpful to like artificially create these vulnerable moments." }\end{array}$ \\
\hline $\begin{array}{l}\text { More emotional effort from } \\
\text { managers }\end{array}$ & $\begin{array}{l}\text { "Actually, that was an insight I had more recently that just, which I'm sure some other people have talked about, but I feel like as a leader, I need } \\
\text { more emotional support. Okay? I'm like, I don't think I've ever leaned on my HR department for emotional support like I do here, or I have to here } \\
\text { because, just like, you know, one, hey, what's the emotional tenor of these two people that are asking really hard questions for me or how do I } \\
\text { navigate this, you know, in a remote-friendly way. Those kinds of things. I feel like I'm constantly with [HR person], figuring out and plotting and } \\
\text { strategizing how we get through some challenge of working remote." }\end{array}$ \\
\hline
\end{tabular}

And in relation to understanding control-related information:

"So, the standard information, what are you working on and how is it going or what are you struggling with? I mean, frankly, for the most part, I get that through them proactively and asynchronously publishing that but what I need is the extra context, you know, the story behind the story. Um, and that's why that's what I focus on".

The concept of missing context occurred frequently in interviews: "I mean, I think the most, the constant thing that we're always talking about and I really wasn't that aware of beforehand is context, context, context".

\subsection{Unknowns Increase}

Managers note greater uncertainty and greater risk of miscommunication in distributed teams. They felt it was easy to misunderstand each other's intent and that communication can easily become 'out of context'.

Uncertain, incomplete or delayed communication translates into potential risks for managers. For example, meetings are often used to ensure that everyone is aligned on priority and strategy. However, if the team is spread across multiple time zones, it can be difficult for the whole team to meet 
which creates the potential for misalignment. When a misalignment does occur, it may take longer for the manager to notice and correct because they may not overhear discussions or observe a staff member's confusion or misdirected work effort.

Managers also felt it is easier to track the productivity of their remote staff than to identify issues with morale or engagement. Several managers used the example that in the office you can pick up small clues that someone may be less engaged when their behavior changes - for example, they may begin to arrive at work slightly later, talk less with their colleagues, or generally look less happy. Changes in work hours can be difficult to track when staff are in different time zones, and unhappy staff may "put on a good face" for the duration of video calls. Managers are aware that working at a distance can create barriers to communication: if someone is unhappy, uncertain about their own performance, or feeling at risk, communicating that to their manager may not be their first instinct. They may instead seek to preserve the appearance of success and thus keep problems under cover. Managers are aware that their staff may not be willing or able to be completely honest about their situation. Communication cannot be relied upon to be complete.

This uncertainty is not limited to staff morale or engagement. As mentioned earlier, when it becomes difficult to observe staff behavior in person, one might assume the focus shifts to measuring outputs. Indeed, some managers felt that working remotely encourages an approach of "measuring the work, not the micromanaging the process", and that this is one reason why, in their view, remote work is superior to traditional, co-located work.

However, when queried about how they measured work, most managers were hesitant to specify metrics. Several managers pointed to the difficulty in creating reliable metrics for technical, creative or problem-solving roles like software development. While managers do track productivity and changes in productivity, for many roles this was more loosely defined than organizational control literature suggests. Even the managers dedicated to 'managing the work' acknowledged the importance of contextualizing what data they did have.

The data shows that managers recognize that problems with staff engagement may be difficult to spot because distance means fewer opportunities for subtle observation. Managers also perceive increased risk from miscommunication and misalignment compared to working co-located with staff. Few managers are willing to rely on formal or explicit metrics. Managers appear to respond to these challenges in two ways: by increasing the amount of work effort, and by increasing the emphasis on relationships.

\subsection{Effort Amount Changes}

Managers often reported they find managing remote staff to be more work than managing co-located staff. This is particularly salient for managers managing both co-located and remote staff at the same time, perhaps because of the constant comparison between the two styles of interaction.

Managers find the extra effort manifests in several ways. When staff are spread across multiple time zones, managers feel they need to be available beyond normal hours, thereby extending their working day. Some managers adapt by setting expectations with their team about their availability.

Managers also find processes that occur naturally when working co-located require more effort and intentionality when managing remotely. Managers often used the word 'intentionality' when describing the extra effort distributed work requires. Intentionality is required in creating culture, creating effective communication norms, on-boarding and socializing new staff.

Distributed work frequently involves asynchronous work, either because staff are in different time zones or because distance and communication technologies hinder short, spontaneous interactions. Asynchronous work leads to a shift from ephemeral, spoken communication towards a greater reliance on and creation of explicit, written information. Managers in distributed teams encourage their team to create recorded information: logs in chat rooms, email threads, recorded video calls, extensive documentation to support asynchronous work, shared online project tracking tools and work repositories. Managers acknowledge this requires more work, but also feel it generates efficiencies.

The large quantities of explicit information also adds to managers' workloads. Keeping up with communication in multiple channels is timeconsuming and there's a concern that important updates may be missed. While individual team members may be able to limit the communication they track to just what is relevant to their role, managers may need to be aware of what is happening with every role in the team.

In summary, managers felt that managing remote staff took more time and effort than the equivalent co-located team. Managers often felt it was necessary to have a smaller team when managing remote staff or that distributed work may be difficult to scale up for larger organizations. 


\subsection{Effort Type Changes}

A notable finding from manager interviews was the strong emphasis on relationships. In some ways, this seems counterintuitive given that managers might only meet their staff in person once or twice a year, and given that managers themselves might expect a shift to 'managing the work' (and therefore, perhaps, less emphasis on people).

The first place the focus on relationships was evident was the emphasis on one-on-one meetings between managers and their staff. While one-on-ones are common practice in many organizations, managers with remote staff characterized their oneon-ones as consistent, essential, and necessary. Oneon-ones were frequent: managers often met one-onone with their remote staff every week or every two weeks for large teams; and lengthy: one-on-ones would be at least 30 minutes and it was not unusual for managers to report they would spend an hour or more meeting one-on-one with their staff. This represents a considerable time investment on the manager's part and likely contributes to concerns about the ability to manage larger teams.

Furthermore, managers explicitly used their oneon-ones to get to know the individuals on their team, to understand how they are feeling and what is happening in their lives both at work and outside of work. Many of the managers discussed the important role that personal, non-work-related information played in their remote teams. Managers encourage, and in some cases direct, their staff to bring more of their personality and personal life into the workplace.

Some managers went to considerable effort to get to know their staff. One manager would set aside hours for long one-on-ones with new staff, talking deeply about their personal history, their personality, and their aspirations. Another stated that "So, you know, one thing is from the beginning I try to establish very intimate, open, vulnerable relationships with my team members" and joked that in some cases, it could take years of constant effort to get to that point.

Managers value that these relationships encourage more information sharing from their staff, for example: "Build your rapport, probably over everything. It was quite humbling to me about some of the information my staff would share because I'd done that. And it helped an awful lot actually in my management of the staff to know that they were really struggling this month with [personal issues]. That, you know, in terms of being able to work with them and the company outcomes ... I'd probably put that up as one of my top one or two things to do with a remote team.".

Another manager, explaining the effort he put into developing close relationships with his team, said: "it just provides a lot of context to really understand who they are", which enabled him to better understand people's behaviors. He felt that knowing individuals well allowed him to be a more effective manager.

Establishing these relationships often requires an emotional investment from the manager, which managers can find emotionally taxing. This represents a considerable investment both in terms of time and emotional energy on the part of the managers.

Overall, managers do not emphasize output controls but rather increase their effort and strengthen relationships with staff.

\section{Discussion}

Managers show some distinctive adaptation in distributed teams. First, they perceive more uncertainty, with a higher risk of miscommunication and misalignment. Manager respond to perceived uncertainty by increasing their work effort; specifically, by working extra hours, through the intentional creation of culture and norms, and an emphasis on encouraging explicit written and recorded information. Despite creating large quantities of explicit and recorded information, and shared, open data on work progress, managers rarely rely on metrics.

Managers also respond by strengthening and deepening relationships with their staff by encouraging the sharing of personal information both in one-on-ones and in the workplace, even though this can be emotionally taxing for the manager.

The increased effort and effort focus, particularly the focus on relationships, can be explained if we incorporate the role of context. From lower physical proximity, and a lack of true support for context awareness in collaboration technologies, we can predict a reduction in context awareness and contextual information in teams separated by physical distance. This is supported by participant comments.

To solve this, managers can try to increase the amount of context that is available. The increased emphasis on recording large quantities of explicit information suggest that managers are trying to surface more information overall, which is likely to increase the amount of context for any given piece of information. 


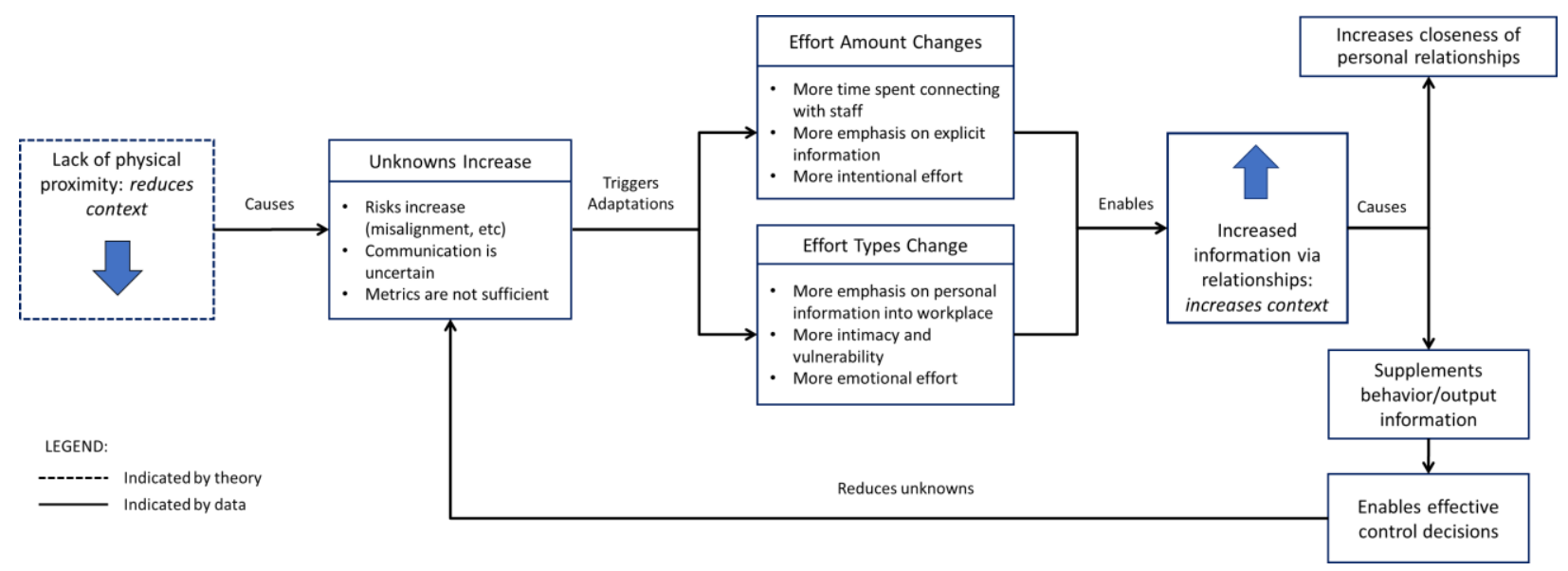

Figure 1: Theoretical model of the role of relationships and context in organizational control in distributed teams

However, the large quantities of explicit recorded information do not seem to be enough. Managers apply considerable energy and effort to interpersonal relationships with their team. These relationships appear to provide a conduit for other important context information. The model, proposed in Figure 1 , functions as follows.

The lack of physical proximity reduces context, which is necessary to interpret information accurately. For managers, information relating to organizational control is particularly critical as it forms a core part of their responsibilities. Control information is often categorized as either generated by monitoring behavior or monitoring outputs. Managers with remote staff monitor for changes in both behavior (though this shifts to being largely communication behavior) and work output to indicate potential problems. However, on its own neither type of information is sufficient - both need context to be interpreted correctly. This is particularly pertinent for behavior controls where accurately interpreting the meaning of an individual's actions is likely to benefit from knowing more about that individual and understanding the context the action occurred in.

To provide more context, managers increase the amount of effort and the focus on relationships. Relationships provide a conduit for information about individuals which supplements the more traditionally recognized behavior and output information. This allows the manager to more effectively identify, diagnose, and choose corrective actions for potential or current problems, thereby allowing the manager to more effectively enact day-to-day organizational control.

The emphasis on relationships generated a particularly counter-intuitive finding: many managers, particularly those with entirely remote teams, reported feeling closer to their team than they would if working in the same office.

"I would say it takes, it took me longer to form connections at [Company] but they are also, I think, deeper than other work connections I've had."

Another manager relayed a story about a team member which suggested the manager was aware of quite personal details of that person's life. I asked if she felt she knew more about her team's personal lives than she might if she was working with them in an office. She replied:

"I do, actually. So, we have this group [chat] and it's just, I actually feel more connected."

As expected, there seems to be a relationship between the amount the manager invests in relationships and reports of feeling very close to their team.

\section{Conclusion and Implications}

These findings highlight a paradox in distributed work: managers feel closer to remote staff as a consequence of 'managing' the distance between them. This research shows that with remote working, managers require more context to implement organizational control, and relationships provide an important source of context. Therefore managers develop close relationships with their staff.

This finding has two notable implications. The first is that organizational control literature has overlooked the importance of context in interpreting control-related information. If we think of traditional, co-located workplaces as the default setting for organizational control, and note that working in physical proximity provides a high level of context information, then traditional, co-located work may be a 'high-context' environment, where a great deal of context information is available by virtue of physical 
proximity. When organizational control shifts to distributed work, which is arguably 'low-context', the role of context in interpreting organizational control information is made more vivid by its absence, and the effortful steps that managers must take to compensate.

The importance of context in interpreting organizational control information helps explain why, for example, organizations tend to shift to more objective, quantitative financial controls as they grow and become more horizontally and vertically differentiated [38] or why managers are more inclined to use output control as their knowledge of task processes decreases [39].

Organizational control research categorizes controls as formal or informal, coercive or enabling, direct or indirect $[4,40]$; to identify how and where controls should be used it is also necessary to understand them as highly context-dependent or more context-independent.

Second, these findings have practical and theoretical implications for distributed teams. Practically, managers need to be aware that organizational control mechanisms that have worked smoothly in co-located settings may not work well in distributed settings. Specifically, they need to be aware that choosing highly context-dependent controls, that depend for example on understanding a great deal about an individual to interpret their performance, may require significantly more time and effort to gather the context necessary to make use of the information these controls provide. This also helps explain why managers feel that managing distributed teams is more difficult than managing a co-located team.

Theoretically, this research increases our understanding of organizational control enactment in distributed teams and the adaptations that managers make when managing staff who work remotely. It highlights the importance of relationships and provides a theoretical framework that can be tested with further empirical research. Furthermore, trust is one of the most studied variables in distributed team literature [10] and may be critical to success [e.g. 41]. However, trust scholars have not reached consensus on when control may help or hinder trust development [18]. This research describes a route where organizational control enactment significantly increases trust and highlights the importance of trust for effecting organizational control. Given the importance of trust in distributed teams, this warrants further investigation.

This proximity paradox presents an intriguing new perspective on organizational control and relationships within distributed teams, and points to the potential for future research in areas of control and trust in distributed teams.

\section{References}

[1] J. L. King and R. L. Frost, "Managing distance over time: The evolution of technologies of dis/ambiguation," Distributed work, pp. 3-26, 2002.

[2] M. O'Leary, W. Orlikowski, and J. Yates, "Distributed work over the centuries: Trust and control in the Hudson's Bay Company, 1670-1826," Distributed work, pp. 27-54, 2002.

[3] J. M. Jones. "In U.S., Telecommuting for Work Climbs to 37\%." Gallup. https://news.gallup.com/poll/184649/telecommutin g-work-climbs.aspx (accessed 17 May, 2019).

[4] L. B. Cardinal, M. Kreutzer, and C. C. Miller, "An Aspirational View of Organizational Control Research: Re-invigorating Empirical Work to Better Meet the Challenges of 21st Century Organizations," Academy of Management Annals, vol. 11, no. 2, pp. 559-592, 2017.

[5] E. S. Bernstein, "Making transparency transparent: The evolution of observation in management theory," Academy of Management Annals, vol. 11, no. 1, pp. 217-266, 2017.

[6] G. Piccoli and B. Ives, "Trust and the unintended effects of behavior control in virtual teams," (in English), MIS Quarterly, vol. 27, no. 3, pp. 365395, 2003.

[7] A. Mitchell and I. Zigurs, "Trust in virtual teams: solved or still a mystery?," ACM SIGMIS Database, vol. 40, no. 3, pp. 61-83, 2009.

[8] C. Breuer, J. Hüffmeier, F. Hibben, and G. Hertel, "Trust in teams: A taxonomy of perceived trustworthiness factors and risk-taking behaviors in face-to-face and virtual teams," Human Relations, 2019 , doi: https://doi.org/10.1177/0018726718818721.

[9] A. Pinsonneault and O. Caya, "Virtual teams: What we know, what we don't know," International Journal of e-Collaboration (IJeC), vol. 1, no. 3, pp. 1-16, 2005.

[10] L. L. Gilson, M. T. Maynard, N. C. Jones Young, M. Vartiainen, and M. Hakonen, "Virtual Teams Research: 10 Years, 10 Themes, and 10 Opportunities," Journal of Management, vol. 41, no. 5, pp. 1313-1337, 2015.

[11] S. Raghuram, N. S. Hill, J. L. Gibbs, and L. M. Maruping, "Virtual Work: Bridging Research Clusters," Academy of Management Annals, vol. 13, no. 1, pp. 308-341, 2019.

[12] M. B. Watson-Manheim, "Discontinuities, Continuities, and Hidden Work in Virtual Collaboration," in Collaboration in the Digital Age: Springer, 2019, pp. 121-132.

[13] L. S. Henderson, R. W. Stackman, and R. Lindekilde, "The centrality of communication norm alignment, role clarity, and trust in global project 
teams," International Journal of Project Management, vol. 34, no. 8, pp. 1717-1730, 2016.

[14] P. J. Hinds and S. P. Weisband, "Knowledge sharing and shared understanding in virtual teams," Virtual teams that work: Creating conditions for virtual team effectiveness, pp. 21-36, 2003.

[15] C. D. Cramton, "Insights for Culture and Psychology from the Study of Distributed Work Teams," in Handbook of Advances in Culture and Psychology, Volume 6. New York: Oxford University Press, 2016.

[16] J. Webster and D. S. Staples, "Comparing Virtual Teams to Traditional Teams: An Identification of New Research Opportunities," in Research in Personnel and Human Resources Management, vol. 25, (Research in Personnel and Human Resources Management, no. 25): Emerald Group Publishing Limited, 2006, pp. 181-215.

[17] M. Kreutzer, L. B. Cardinal, J. Walter, and C. Lechner, "Formal and informal control as complement or substitute? The role of the task environment," Strategy Science, vol. 1, no. 4, pp. 235-255, 2016.

[18] C. P. Long and S. B. Sitkin, "Control-trust dynamics in organizations: identifying shared perspectives and charting conceptual fault lines," Academy of Management Annals, vol. 12, no. 2, pp. 725-751, 2018.

[19] L. J. Kirsch, "The management of complex tasks in organizations: Controlling the systems development process," Organization Science, vol. 7, no. 1, pp. 121, 1996.

[20] L. B. Cardinal, S. B. Sitkin, and C. P. Long, "A configurational theory of control," Organizational control, vol. 51, no. 79, pp. 85-100, 2010.

[21] L. J. Kirsch, "Portfolios of Control Modes and IS Project Management," Information Systems Research, vol. 8, no. 3, pp. 215-239, 1997.

[22] L. B. Cardinal, S. B. Sitkin, and C. P. Long, "Balancing and Rebalancing in the Creation and Evolution of Organizational Control," Organization Science, vol. 15, no. 4, pp. 411-431, 2004.

[23] W. G. Ouchi, "The relationship between organizational structure and organizational control," Administrative science quarterly, pp. 95-113, 1977.

[24] N. B. Kurland and T. D. Egan, "Telecommuting: Justice and control in the virtual organization," (in English), Organization Science, vol. 10, no. 4, pp. 500-513, 1999.

[25] N. B. Kurland and C. D. Cooper, "Manager control and employee isolation in telecommuting environments," The Journal of High Technology Management Research, vol. 13, no. 1, pp. 107-126, 2002.

[26] A. Felstead, N. Jewson, and S. Walters, "Managerial control of employees working at home," British Journal of Industrial Relations, vol. 41, no. 2, pp. 241-264, 2003.

[27] G. Piccoli, A. Powell, and B. Ives, "Virtual teams: team control structure, work processes, and team effectiveness," Information Technology \& People, vol. 17, no. 4, pp. 359-379, 2004.

[28] J. L. Gibbs, A. Sivunen, and M. Boyraz, "Investigating the impacts of team type and design on virtual team processes," Human Resource Management Review, vol. 27, no. 4, pp. 590-603, 2017.

[29] C. Stoak Saunders and M. K. Ahuja, "Are all distributed teams the same? Differentiating between temporary and ongoing distributed teams," Small Group Research, vol. 37, no. 6, pp. 662-700, 2006.

[30] R. K. Purvanova, "Face-to-face versus virtual teams: What have we really learned?," The Psychologist-Manager Journal, vol. 17, no. 1, pp. 2-29, 2014.

[31] "Context." Cambridge Dictionary. https://dictionary.cambridge.org/dictionary/english/ context (accessed 29 August, 2019).

[32] T. Gross, "Supporting effortless coordination: 25 years of awareness research," Computer Supported Cooperative Work (CSCW), vol. 22, no. 4-6, pp. 425-474, 2013.

[33] C. Gutwin and S. Greenberg, "The importance of awareness for team cognition in distributed collaboration," 2001.

[34] K. Schmidt, "The Problem with 'Awareness'," Computer supported cooperative work., vol. 11, $\mathrm{p}$. 285, 2002.

[35] K. G. Corley and D. A. Gioia, "Identity Ambiguity and Change in the Wake of a Corporate Spin-Off," Administrative Science Quarterly, vol. 49, no. 2, pp. 173-208, 2004.

[36] D. A. Gioia, K. G. Corley, and A. L. Hamilton, "Seeking Qualitative Rigor in Inductive Research: Notes on the Gioia Methodology," Organizational Research Methods, vol. 16, no. 1, pp. 15-31, 2012.

[37] J. Saldaña, The coding manual for qualitative researchers / Johnny Saldaña, 3E [Third edition].. ed. Los Angeles, Calif. London : SAGE, 2016.

[38] R. E. Hoskisson, M. A. Hitt, and C. W. L. Hill, "Managerial Incentives and Investment in R\&D in Large Multiproduct Firms," Organization Science, vol. 4, no. 2, pp. 325-341, 1993.

[39] W. G. Ouchi and M. A. Maguire, "Organizational Control: Two Functions," Administrative Science Quarterly, vol. 20, no. 4, pp. 559-569, 1975.

[40] L. Errichiello and T. Pianese, "Organizational Control in the Context of Remote Work Arrangements: A Conceptual Framework," in Performance Measurement and Management Control: Contemporary Issues: Emerald Group Publishing Limited, 2016, pp. 273-305.

[41] R. C. Ford, R. F. Piccolo, and L. R. Ford, "Strategies for building effective virtual teams: Trust is key," Business Horizons, vol. 60, no. 1, pp. 25-34, 2017. 
Page 450 